gives much useful information on the subject. Up to the present, sulphuric acid has proved to be the most effective chemical for the purpose, as it kills a wide range of weeds and is quick acting even in dull weather. Its highly corrosive properties, however, make it difficult to handle; so copper chloride and dinitro-ortho-cresol (D.N.O.C.) are suggested as alternatives. Directions for the use of all three substances are given, and comparison made between the concentra tions of spray required in each case for the eradication of a number of common weeds. As regards time of spraying, rather more latitude is possible with copper chloride and dinitro-ortho-cresol than with sulphuric acid, which kills weeds only in the seedling stage, but usually the acid has a slight advantage if the weather is cold and dull. Full instructions are given in the use of these spray materials, and any precautions necessary for the protection of the operator or care of equipment clearly mentioned.

\section{West of Scotland Field Studies Council}

IN 1944 members of the Glasgow and Andersonian Natural History and Microscopical Society, including Dr. Inglis Cameron, carried out preliminary work which resulted in the inauguration in April 1945 of the West of Scotland Field Studies Council. On the Council are representatives of youth organizations, scientific societies, colleges and the University of Glasgow. Prof. Balfour Brown and Prof. C. M. Yonge, who have connexions with similar organizations in the south of Britain, are also on the Council. The Council is mainly, but not exclusively, concerned with the popularization of field studies. Its membership is widely representative, and includes amateur and professional naturalists, educationists, representatives of the Scottish Youth Hostels Association, Boy Scouts, etc. Its constitution provides it with useful powers of co-option. The Council is anxious to get in touch with other organizations of a similar nature, so that some type of co-operation may be established and there may be a free exchange of ideas. It has already set up panels of lecturers and outdoor guides, and is considering the preparation of guide-books to the natural history of the west of Scotland. The chairman is Prof. John Walton; the honorary secretary is Dr. T. Gregory Absalom, Art Galleries and Museum, Kelvingrove, Glasgow, C.3, to whom communications should be addressed.

\section{Durban Museum and Art Gallery}

IN the annual report for 1943-44 of the Durban Museum and Art Gallery, it is reported that their position as institutions of visual education and æsthetic enjoyment has been well maintained; but reference is made to the now common need among museums in all parts of the world for further and more suitable accommodation. Besides the usual routine work, many public lectures were given in the Museum and Art Gallery throughout the year, and there was much activity in connexion with the school services. The showing of educational films evidently takes a prominent place in these services. In reference to adult education, it is of interest that the South African Minister of Education appointed a committee to inquire into, and report upon, the part played by the Museum and Art Gallery in this realm of their activities. One of the photographic plates in this report depicts an interesting group of carved stone figures entitled "Baya Huba", by Mary Stainbank; this was recently acquired by the Art Gallery.

\section{Biochemical Research Foundation of the Franklin Institute}

IN Reports of the Biochemical Research Foundation of the Franklin Institute $(7 ; 1942-43)$, stress is laid on the. importance of co-ordination of the sciences of physics, chemistry and biology. By this means it is often possible to obtain a comprehensive view of a problem, whereas the isolated methods of the past would only come to an impasse. There are more scientific trained personnel in this Institute than in almost any college, and, free from the burden of teaching, all are co-ordinated and organized towards the special end. Direction of research towards certain projects is thus possible, and groups of scientific workers of varied character together with apparatus of unique quality are brought to bear on the elucidation of any problem. An example of this type of group co-operative work is the successful separation by physico-chemical methods followed by biological study of certain surface antigens of the typhoid bacillus having high immunizing powers without any great degree of toxicity.

\section{Announcements}

Mr. Roy InNes has been appointed general secretary of the Association of Scientific Workers. Mr. Innes took a degree in mathematics and physics at the University of Manchester in 1937. For a time he was a science teacher, and in 1939 entered the newly formed Operational Research Section attached to Fighter Command, R.A.F. He succeeds Mrs. Reinet Fremlin, who has been with the Association for eight years.

AN open meeting to discuss "Social Security for Chemists" has been arranged by the London Section of the British Association of Chemists. It will be held at the Assembly Hall, Royal Empire Society, Northumberland Avenue, at 6.30 p.m. on September 19 .

Voks Bulletin No. 6, of the U.S.S.R. Society for Cultural Relations with Foreign Countries, includes a tribute to Mendeléeff, by M. Pervukhim, People's Commissar of the Chemical Industry of the U.S.S.R., in connexion with the seventy-fifth anniversary of the discovery of the periodic law, and an article by the late A. Fersman, of the Academy of Sciences of the U.S.S.R., on the periodic law and its significance for natural science, in which its bearing on geochemistry as well as on cosmic processes and theoretical chemistry generally are considered.

THE following appointments have been made in the newly formed Department of Animal Health at the University Gollege of Wales, Aberystwyth : $\mathrm{Mr}$. R. Phillips, formerly senior lecturer in agriculture, to undertake research in animal husbandry and the administration of investigational centres; Dr. W. C. Evans, at present biochemist to the Inoculation Department, St. Mary's Hospital, London, to be special lecturer in biochemistry; Mr. E. Parker Pollard has been seconded by the Cooper Technical Bureau for research in parasitology ; Mr. D. N. Fidler, to be research assistant (animal husbandry); Mr. R. A. Evans, at present of Crooke's Laboratories, and Mr. A. W. Davies, formerly of the Dunn Nutritional Laboratory, Cambridge, to be research assistants (biochemistry); Mr. T. R. Thomas, Carmarthen, to be consulting veterinary surgeon. 